Revista da Rede Brasileira de História da Geografia e Geografia Histórica

\title{
Tradições cartográficas e fixação de fronteiras na independência brasileira
}

Os mapas como um meio de delimitar o território

Traditions cartographiques

Cartographic traditions

\section{Enali De Biaggi}

\section{(2) OpenEdition \\ Journals}

\section{Edição electrónica}

URL: https://journals.openedition.org/terrabrasilis/1094

DOI: 10.4000/terrabrasilis. 1094

ISSN: 2316-7793

\section{Editora}

Rede Brasileira de História da Geografia e Geografia Histórica

\section{Refêrencia eletrónica}

Enali De Biaggi, «Tradições cartográficas e fixação de fronteiras na independência brasileira», Terra Brasilis [Online], 4 | 2015, posto online no dia 12 fevereiro 2015, consultado o 05 dezembro 2022. URL: http://journals.openedition.org/terrabrasilis/1094 ; DOI: https://doi.org/10.4000/terrabrasilis. 1094

Este documento foi criado de forma automática no dia 5 dezembro 2022.

All rights reserved 


\title{
Tradições cartográficas e fixação de fronteiras na independência brasileira
}

\author{
Os mapas como um meio de delimitar o território
}

Traditions cartographiques

Cartographic traditions

Enali De Biaggi

1 O trabalho que apresentamos aqui faz parte de um projeto mais amplo, onde nosso interesse era demonstrar como a cartografia refletiu os desafios territoriais de um país que não deixou de crescer e integrar um imenso território que ocupa quase a metade da América do Sul. O estudo da cartografia brasileira realizado então, (De Biaggi, 2000) apontava três momentos importantes da construção territorial do país: em um primeiro tempo aparecem os contornos de um espaço que se estrutura, afirmando novas soberanias (1500-1930); em seguida observa-se um processo de consolidação do domínio territorial interno, através de projetos de levantamento sistemático do país (1930-1980); enfim, em um período de grandes transformações sociais e tecnológicas, o uso da cartografia se diversifica e atinge novos grupos em um momento de abertura política (1980-2000). A cada momento, o trabalho com mapas vem dar corpo às ambições políticas de elites luso-brasileiras, fornecendo uma imagem concreta dos espaços em vias de apropriação, reforçando o domínio sobre as terras e os homens que nelas se encontram. Nesse sentido consideramos que a cartografia não é uma simples técnica, mas um verdadeiro discurso que contribui para a compreensão e a estruturação da sociedade brasileira em seu território.

o período da independência brasileira é emblemático de um duplo movimento: por um lado há a incorporação de tradições portuguesas originárias do período colonial, ao mesmo tempo, aparecem novas características que formarão a base da cartografia nacional brasileira. Da mesma maneira que seus equivalentes europeus, a diplomacia que se instala no Brasil independente demonstra uma grande habilidade em usar mapas 
de maneira eficaz na defesa de limites territoriais, face à vizinhos que se encontram todos, em fase de delimitações de fronteiras. As elites brasileiras serão capazes de fomentar a produção de novas imagens que possam contribuir para criar uma aura "civilizada" de um Estado em busca de reconhecimento nacional e internacional, sem deixar de se apoiar nos antigos mapas feitos na época colonial. Se o modelo europeu parece onipresente, ele será rapidamente confrontado com as novas condições existentes, levando-o a se adaptar, para servir à afirmação do poder central de um novo país, em terras e condições americanas.

O século XIX marca o início de uma produção oficial de mapas realizados localmente produção que poderá se apoiar sobre um acervo histórico cartográfico, negociado paralelamente ao reconhecimento da soberania nacional. Assim, as imagens criadas durante mais de 300 anos de domínio colonial permitirão a transição a um Estado independente, onde a cartografia auxilia a afirmação de políticas que delimitarão o novo país que se forma.

\section{Diplomacia e organização cartográfica}

4 A instalação da corte portuguesa no Brasil em 1808, como um meio de proteger a coroa portuguesa das invasões napoleônicas, inaugura o ciclo de transformações institucionais que marcam o século XIX em terras brasileiras. Tornando-se o centro do império português, e sob a esfera determinante da Inglaterra, a América portuguesa adquire enfim a autorização de confeccionar e arquivar localmente mapas e outros documentos de análise espacial. São assim criadas a Imprensa e a Biblioteca Real, bem como os Arquivos Militares, que receberão todos os mapas, planos topográficos ou de fortificações e todas as resenhas territoriais portuguesas, evitando que esses objetos, considerados estratégicos, sejam recuperados pelas tropas francesas no momento da invasão de Portugal em 1811.

5 A proximidade administrativa não conseguirá, no entanto, evitar que os elos que ligam a colônia à metrópole sejam progressivamente rompidos. Em 1810 o Brasil se transforma em protetorado britânico, graças ao Tratado de Aliança, Comércio e Navegação feito com a coroa inglês. Face à série de revoltas liberais que ocorrem tanto em Portugal quanto no Brasil, a divisão do reino se concretiza em 1822, deixando nas terras americanas uma dinastia independente. O Brasil rompe com a metrópole, mas mantém como chefe de governo um príncipe português que garante o regime escravocrata de produção, mesmo que este já tenha sido objeto de críticas da parte dos aliados ingleses. Tomando a forma de um Império, o novo Estado brasileiro se inspira no centralismo napoleônico para se impor diante das inúmeras divergências internas entre as elites e das revoltas separatistas que ocorrem em várias partes do Império: a figura centralizadora do imperador é o eixo em torno do qual se passa a criar uma nação em busca de reconhecimento exterior, em um território ainda mal integrado.

\section{A busca do reconhecimento internacional: a visão do Brasil nos mapas europeus da época da independência}

6 No exterior, a Inglaterra foi o intermediário diplomático e econômico, capaz de integrar a existência da nova nação no campo de ação de sua política imperialista. De fato, em 1825 o embaixador inglês conseguirá a assinatura de um acordo de paz e 
amizade entre Portugal e o Brasil mediante indenizações ${ }^{1}$, acordo que será de interesse para outras nações, tais como a França e os Estados Unidos, atentos à importância de um país de tamanhas proporções. Uma comparação entre mapas de origens diferentes pode ilustrar de maneira interessante as visões divergentes no período próximo à independência.

7 Um mapa inglês de 1822, mesmo apresentando vários erros de representação como a localização do Trópico de Capricórnio a $18^{\circ}$ de latitude sul, demonstra bem o amplo contato existente entre os dois países: fala-se de "Brasil" (escrito sem $z$ em um mapa onde as legendas são todas em inglês); apresenta-se a fachada atlântica sem insistir nos limites ocidentais nem setentrionais da capitania geral do Pará (questões problemáticas tanto para os novos vizinhos, como para as antigas metrópoles). Utiliza-se limites naturais como rios e montanhas desenhados de maneira bastante esquemática para delimitar as "capitanias gerais" do Pará, Maranhão, Goiás, Mato Grosso, São Paulo, Rio de Janeiro, Minas Gerais, Pernambuco (imensa, no extremo noroeste do país) e Bahia (guardando ainda as capitanias de Ilhéus e Porto Seguro, portanto já extintas); o governo do Rio Grande do Sul engloba também o território de Santa Catarina, enquanto os governos de Piauí e Sergipe aparecem delimitados. De maneira geral, o mapa dá a impressão dos grandes traços e articulações internas de um território único, consolidado, longe da série de revoltas e resistências internas que vão aparecer no momento da independência ${ }^{2}$ (ver figura 1a).

Figura 1: O Brasil visto por europeus na época da independência

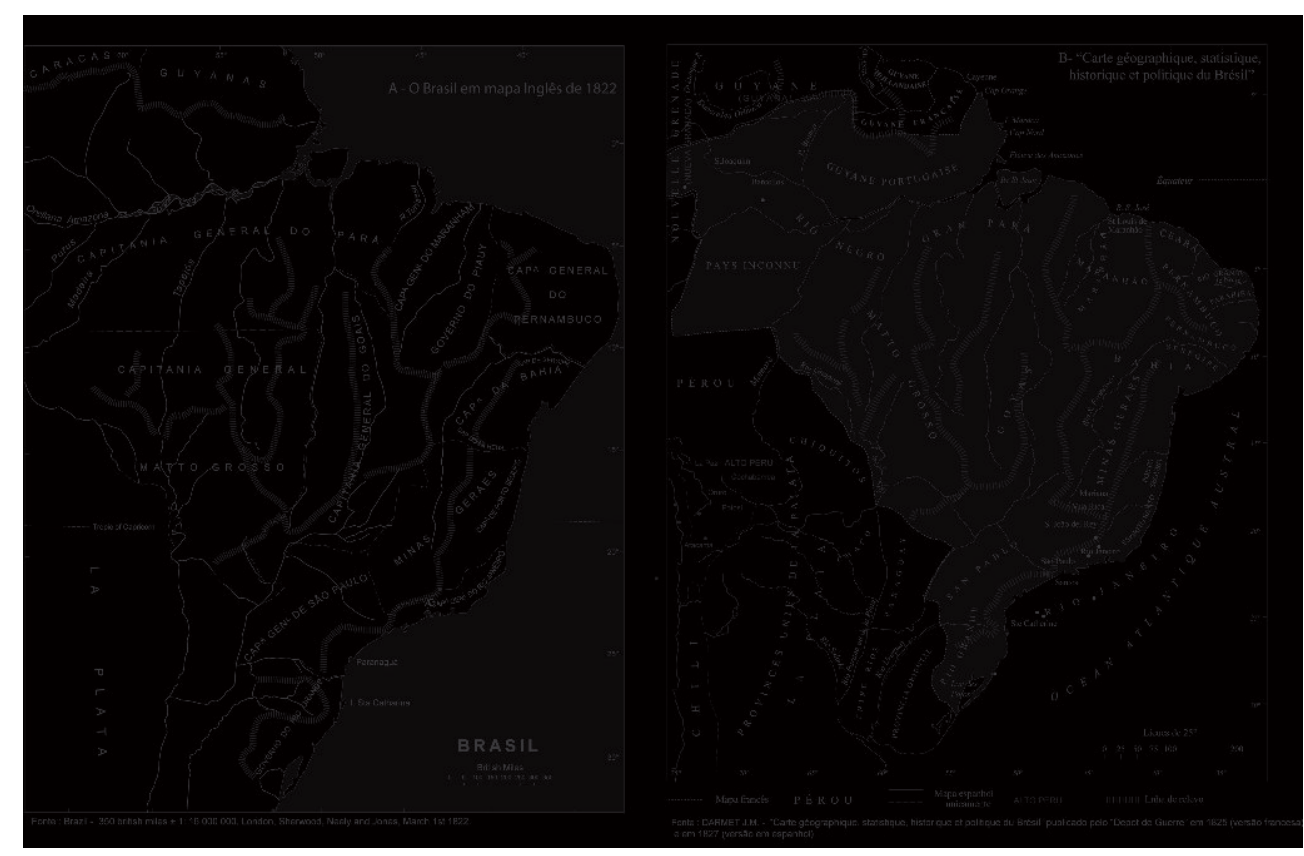

A - O Brasil em um mapa inglês de 1822. B - «Carte géographique, statistique, historique et politique du Brésil

Coleção da Biblioteca Nacional da França

8 Um mapa francês da mesma época (figura 1b), publicado em 1825 no "Depot de Guerre" pelo encarregado de topografia do ministério de relações exteriores francês, J. M. Darmet, mostra uma visão bem mais crítica face ao novo Estado. A "Carte géographique, statistique, historique et politique du Brésil" terá uma edição em espanhol dois anos mais tarde e deixa entrever o interesse suscitado pelo país, que merece um trabalho de 
pesquisa aprofundado. No texto bastante longo que enquadra o mapa, o autor se expressa de maneira que estaria longe de ser elogiosa: a população local é vista como "só aspirando à fortuna pela descoberta de minas", tanto que não se deveria esperar nada da indústria desenvolvida localmente; a capital do Império é descrita como "bem construída, mas muito suja", enquanto a descrição do Pará seria a de uma região "baixa e insalubre". Os únicos locais que escapam às críticas contundentes são a cidade de São Luís (fundada por franceses), e o Rio Grande do Sul, "com um clima muito bom e um solo tão fecundo que é chamado o celeiro do Brasil". o mapa localiza com topônimos as diferentes províncias do Império, porém sem indicar limites e nem o status de cada uma. É necessário ler o texto para compreender que se fala de 14 capitanias, agrupadas em 10 governos gerais, separados em regiões: oeste (Pará, Maranhão, Pernambuco e Alagoas), leste (Bahia, Rio de Janeiro, São Paulo e Rio Grande do Sul) e interior (Minas Gerais, Matto Grosso e Goyas). Em cada governo geral são citados os governos secundários e os distritos que os compõem, de forma a criar um quadro global da estrutura administrativa da época e o peso demográfico de cada uma de suas partes:

\begin{tabular}{|c|c|c|c|}
\hline $\begin{array}{l}\text { Governos } \\
\text { Gerais }\end{array}$ & $\begin{array}{l}\text { Governos } \\
\text { Secundários }\end{array}$ & Distritos & \\
\hline $\begin{array}{l}\text { PARA } \\
800000 \text { almas }\end{array}$ & & $\begin{array}{l}\text { Rio Negro, Macapá / Solimões, Guyane / } \\
\text { Tocantins, Xingu,Tapajós, Madeira }\end{array}$ & OESTE \\
\hline $\begin{array}{l}\text { MARANHÃO } \\
300000 \text { almas }\end{array}$ & PIAUHY & $\begin{array}{l}\text { Maranhão, Piauhy, Pará, Rio Negro, Seará } \\
\text { Grande }\end{array}$ & MARITIMO \\
\hline $\begin{array}{l}\text { PERNAMBUCO } \\
500000 \text { almas }\end{array}$ & SEARA, PARAHIBA & $\begin{array}{l}\text { Olinda, Recife, Alagoas, Sertão de } \\
\text { Pernambouc }\end{array}$ & \\
\hline $\begin{array}{l}\text { BAHIA } \\
600000 \text { almas }\end{array}$ & $\begin{array}{l}\text { SEREGIPE, } \\
\text { ESPÍRITO SANTO }\end{array}$ & $\begin{array}{l}\text { Ilheus, Baya, Jacobina, Seregype, Porto } \\
\text { Seguro, Espíritu Santo }\end{array}$ & \\
\hline $\begin{array}{l}\text { RIO DE JANEIRO } \\
700000 \text { almas }\end{array}$ & & $\begin{array}{l}\text { Rio de Janeiro, Goytacazes, Cabo Frio, Ilha } \\
\text { Grande, Parahiba, Santa Catarina }\end{array}$ & LESTE \\
\hline $\begin{array}{l}\text { SAN PAULO ou ST } \\
\text { PAUL } \\
50000 \text { almas }\end{array}$ & & Paranaguá, Saint Paul, Ita & \\
\hline $\begin{array}{l}\text { RIO GRANDE DO } \\
\text { SUL } \\
200000 \text { almas }\end{array}$ & & Porto Alegre & \\
\hline $\begin{array}{l}\text { MINAS GERAES } \\
500000 \text { almas }\end{array}$ & & $\begin{array}{l}\text { Vila Rica, Serro do Frio, Sabura, Rio dos } \\
\text { Mortes, Paracatu }\end{array}$ & \\
\hline $\begin{array}{l}\text { GOIAS } \\
200000 \text { almas }\end{array}$ & & São João das duas Barras, Vila Boa & INTERIOR \\
\hline
\end{tabular}




\begin{tabular}{|l|l|l|l|}
\hline $\begin{array}{l}\text { MATTO GROSSO } \\
300000 \text { almas }\end{array}$ & Villa Bella, Cuyaba & \\
\hline
\end{tabular}

9 No total, a população ficaria em torno de 4 a 5 milhões de habitantes, divididos da seguinte maneira : 850000 brancos, 160000 negros livres, 430000 pessoas livres de sangue mestiço, 260000 índios, 200000 escravos de sangue mestiço e 1700000 escravos negros ${ }^{3}$. Dessa maneira, pode-se interpretar que, quando o texto indica que todos os brasileiros, com exceção dos empregados domésticos, mendigos e escravos, possuem direitos cívicos e políticos, mais da metade da população seria excluída da constituição que consagrou as liberdades individuais. Com as circunstâncias agravantes de uma instrução pública precária e de uma herança desfavorável (o rei D.JoãoVI teria desejado dominar a América, sem no entanto trazer os benefícios da civilização). Todas as características do país revelam um Estado, cuja existência recente seria ainda bem incerta:

Sous quelque rapport que l'on envisage l'Empire brésilien, sa situation est fausse et périlleuse : vu d'un œil hostile par l'État de Buenos Ayres, dédaigné par la Colombie qui a refusé son alliance, non reconnu des puissances prépondérantes de l'Europe ; en butte à la haine de la mère patrie ; recelant en lui-même tous les germes d'une guerre civile par l'opposition d'intérêts, des mœurs et de l'origine des peuples qui le composent ; on ne saurait prononcer avec assurance que le sort de cet Empire soit désormais dans la balance des Nations. (in "Carte géographique, statistique, historique et politique du Brésil", dessinée, gravée et écrite au Dépôt de Guerre par le français J. M. Darmet, 1825)

É interessante indicar as diferenças de enfoque entre as edições francesa e espanhola deste mapa. Na versão francesa, a fronteira entre as Guianas merece destaque, com uma Guiana Portuguesa bastante dilatada e a menção mesmo de uma "Guiana Portuguesa". No entanto, os topônimos exteriores ao Brasil são bem menos importantes. No mapa em espanhol, os limites ocidentais das Guianas são os únicos que aparecem ao norte do conjunto brasileiro. Ao oeste, o limite ocidental do continente (as costas chilenas) vem completar o traçado das fronteiras internas dos novos países (Peru, Alto Peru, La Plata, Nova Granada) e uma boa parte da toponímia mais abundante é traduzida em espanhol. o traçado das fronteiras meridionais lembra os termos do Tratado de São Ildefonso, sem dar, contudo, aos brasileiros a Lagoa Mirim, sinal de uma posição francesa mais próxima dos interesses de Buenos Aires do que brasileiros. No entanto, o mapa mostra um Brasil que ultrapassa as margens do rio Guaporé e o curso superior do Paraguai, fazendo avançar ao sul o "país desconhecido" brasileiro, habitado por "comonamas" e "curiguereys". Pode-se adivinhar as fronteiras indefinidas, sujeitas às controvérsias históricas dos acordos internacionais e o amplo esforço a ser feito para consolidar regionalmente um Estado novo, face à comunidade de nações.

\section{As missões do Barão de Ponte Ribeiro e as fronteiras continentais}

11 Com a dupla missão de lutar para obter o reconhecimento internacional e ao mesmo tempo definir suas fronteiras, uma nova diplomacia se forma no Brasil de maneira improvisada, até que uma lei crie oficialmente em 1851, o corpo diplomático do Império. 
12 A política exterior do Império, com sua inspiração e referência em nações européias, não mudará radicalmente os argumentos que foram úteis em três séculos de colonização portuguesa. De fato, para reforçar a unidade do conjunto de terras de origem lusitana, as mesmas estratégias portuguesas de controle das duas maiores bacias continentais, a Platina e a Amazônica, são mantidas. Os antigos tratados de limites - principalmente o de Madrid e de São Ildefonso - vêm regularmente à tona, nas negociações entre os representantes políticos dos novos Estados independentes. Mas os brasileiros compreendem rapidamente que o uso dos antigos mapas pode servir de prova, quando se evoca os direitos adquiridos pelo "utis possidetis" para chegar a acordos mais vantajosos para o Brasil't.

13 Entre os novos diplomatas brasileiros, responsáveis pela adoção do argumento do de l'uti possidetis, se destaca o nome do Barão de Ponte Ribeiro. Nas suas inúmeras missões aos países vizinhos, Ponte Ribeiro percebe as vantagens de abandonar a lógica do respeito aos tratados anteriores por uma negociação baseada nos princípios relativos à situação contemporânea dos territórios em questão. Desde 1837 ele expõe suas idéias à chancelaria do Império, até que finalmente, em 1849, elas se tornem a norma geral da diplomacia brasileira.

14 Português de origem, Ponte Ribeiro se tornou brasileiro com a constituição de 1824 e, desde 1825 ele foi enviado como cônsul geral à Madrid para tentar obter o reconhecimento do Brasil independente. Sem sucesso na sua missão inicial (a Espanha só reconhece o Império em 1835), ele retorna à América do Sul para servir como representante brasileiro nos países vizinhos: entre 1829 e 1832, se estabelece no Peru; entre 1833 e 1835, no México, onde participa do primeiro congresso de nações americanas; entre 1836 e 1841 é enviado ao Chile, à Bolívia e ao Peru; durante o Governo Rosas (1842-43), se torna ministro-residente na Argentina. Nesta última posição, é encarregado de informar os países americanos como o Chile, a Bolívia, o Peru, o Equador, a Colômbia e a Venezuela, as razões que levaram o Brasil ao conflito com o governo das Provincias Unidas de la Plata e com o governo de Montevidéu. Enquanto percorria os países limítrofes, o barão aproveitava para colecionar também toda a informação, fosse ela portuguesa ou espanhola e eventualmente útil para esclarecer as fronteiras brasileiras ${ }^{5}$. Quando, em 1853, o barão se torna conselheiro da Secretaria das Relações Exteriores, já havia redigido 45 tratados sobre o conjunto das fronteiras brasileiras ${ }^{6}$.

No momento da redação destes tratados, às vezes orientados pelas negociações do momento, Ponte Ribeiro pôde utilizar o acervo documentário reunido nos Arquivos Militares do Rio de Janeiro. Dos 964 documentos cartográficos reunidos, o barão constituiu quatro grandes grupos: os mapas do Brasil (436); os mapas dos Estados e colônias limítrofes (11); os mapas de Portugal e de suas possessões (446) e enfim os mapas especiais de navegação (71). Ele sugeriu então ao Império três medidas no que concerne à coleção: primeiro, para os mapas do Brasil e dos países vizinhos, que fosse utilizado um exemplar de cada mapa existente em duplicata: segundo, que fosse feita uma cópia dos que existiam em um único exemplar, para mandá-los à Secretaria das Relações Exteriores e finalmente que todas as cartas marinhas fossem enviadas à biblioteca do Ministério da Marinha. Finalmente, propunha à Portugal um acordo para trocar todos os mapas dos domínios portugueses pelos mapas sobre o Brasil presentes nos Arquivos ultra-marinos (Adonias, 1960). 

mais longa a se concretizar. A troca de mapas existentes sobre os dois países teve que esperar até 1863, quando o Barão de Ponte Ribeiro aproveitou uma viagem à Europa para começar as negociações com Portugal. Após um estudo detalhado sobre as cartas, mapas, planos, relatórios e diários que poderiam interessar o país nas questões de fronteiras coloniais, bem como os documentos sobre os acordos que as fixaram, em dezembro 1867, no Instituto Geográfico de Lisboa, foi assinado o protocolo de trocas de documentos escolhidos de cada lado.

guiar a assinatura progressiva de vários tratados com os paises vizinhos (ver figura 2). guiar a assinatura progressiva de vários tratados com os países vizinhos (ver figura 2). Em 1851, Ponte Ribeiro participa a assinatura de um acordo com o Peru, definindo como fronteira a cidade de Tabatinga, a partir da qual uma linha reta direto ao norte deveria encontrar ao rio Japurá, enquanto ao sul o rio Javari marcaria os limites. As diversas vantagens territoriais obtidas pelo Brasil neste tratado estão profundamente baseadas no argumento do uti possidetis, embora fosse dado um direito de navegação aos peruanos, em troca. Este mesmo tipo de transação seria utilizado nos tratados com a Venezuela e a Bolívia, realizadas respectivamente em 1859 e 1867 pelo mesmo Ponte Ribeiro, graças à sua "diplomacia cartográfica".

Figura 2: A indecisão das fronteiras no século CIC, e a contribuição do Barão de Ponte Ribeiro

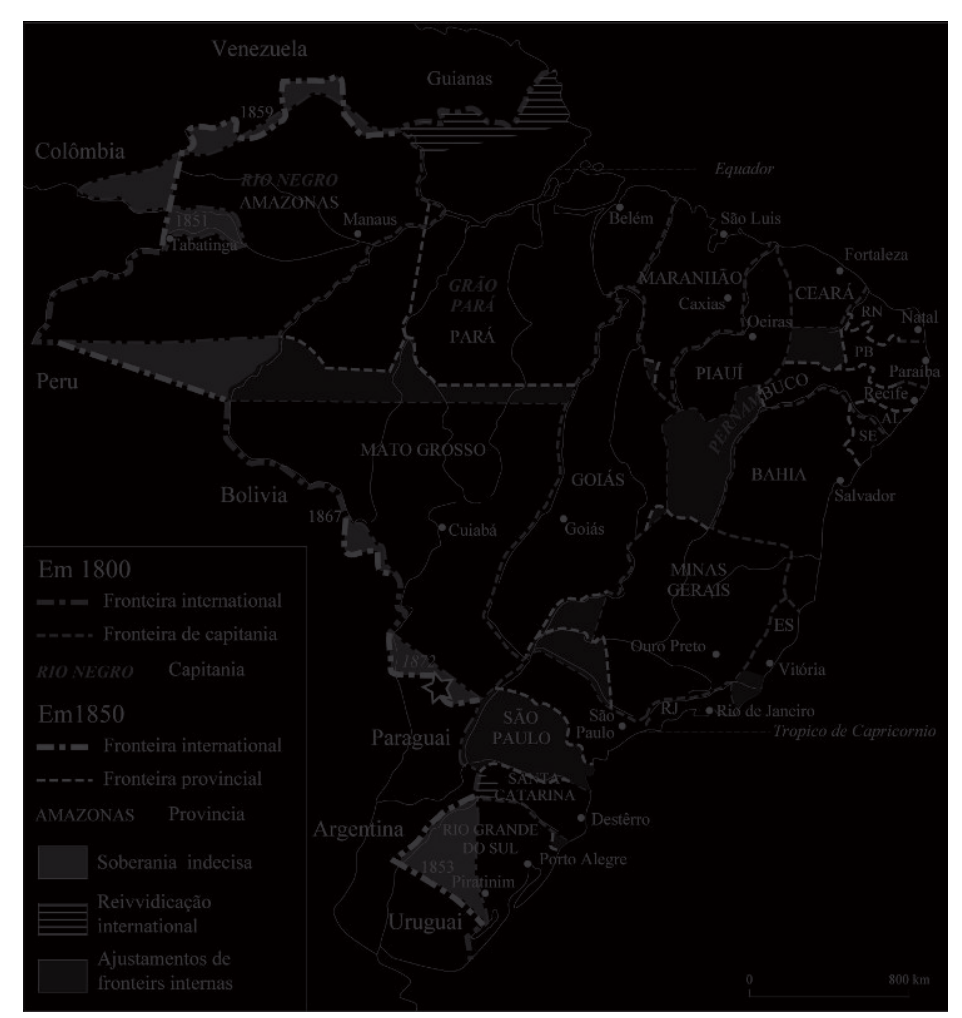

As datas indicam os diferentes tratados negociados pelo Barão de Ponte Ribeiro ao longo do século XIX

Fonte: Droulers, 2001

Em 1853, o Barão já havia participado a assinatura de um acordo definitivo regulamentando a questão das fronteiras com o Uruguai, após o final da Guerra Cisplatina. Esta vez, o problema espinhoso que tantas vezes havia sido objeto de 
tratados coloniais só foi resolvido graças a uma intervenção externa, com a criação de um protetorado britânico capaz de neutralizar as rivalidades na região do estuário platino, traduzindo-se na disputa entre o Brasil e o governo de Buenos Aires. A importância de garantir os limites com o novo Estado da "banda oriental" se exprime na construção da primeira grande rede de triangulação do Império, realizada entre 1852 e 1857 na região de fronteira (Furtado, 1959) ${ }^{7}$.

Os mesmos tipos de litígios fronteiriços influenciariam o tratado com o Paraguai feito em 1872, após uma guerra contra este país, que havia aproximado o Brasil do Uruguai e da Argentina. A respeito do Paraguai, o Barão de Ponte Ribeiro já havia proclamado sua convicção de que, a presença dessa república e do estabelecimento de suas fronteiras, deveria ser primordial para assegurar a unidade interna do país, graças à uma visão estratégica dos meios de integração regional:

A guerra do Paraguai, que será efetivamente um marco para a política imperial como veremos mais tarde, será não somente a ocasião de realizar novos mapas regionais, mas servirá também como anti-exemplo para todos os outros acordos de fronteiras que o Barão de Ponte Ribeiro não conseguiu realizar durante o exercício de suas atividades diplomáticas. Ele deixou o modelo do que se tornaria a prática corrente na definição das novas nações americanas: mais que uma questão de diplomacia, o recurso a mapas e aos técnicos capazes de confeccioná-las, tornou-se regra em todas as comissões de delimitação que se formaram. No caso brasileiro, mais do que seguir os tratados coloniais, o Estado Imperial utilizou a cartografia para testemunhar um controle territorial histórico e real. Esta herança de ocupantes que obtiveram o direito de se estabelecer, graças à garantia de uso prolongado das terras, servirá para justificar a idéia de manutenção de um território único, do "mesmo Brasil fundado pelos colonizadores" (Carvalho, 1939).

21 Sem verdadeira ruptura na estrutura de exploração territorial existente, a cartografia oficial mantém assim as mesmas funções de testemunhar a ocupação do espaço. Os estudos do Barão Ponte Ribeiro e a sua coleção de mais de 500 mapas $^{8}$, bem como os catálogos que organizou, formaram a base da mapoteca da Secretaria das Relações Exteriores, que daria toda a legitimidade ao novo Estado em formação. Além do reconhecimento do novo país, os mapas se apóiam no passado europeu de descoberta, de ocupação e de explorações que se mantiveram até o momento atual, ao mesmo tempo em que buscavam meios de se institucionalizar oficialmente.

\title{
A nova cartografia nacional: atores e perspectivas
}

\author{
"A elite brasileira se considerava como uma parte \\ da civilização européia condenada aos trópicos. A \\ "civilização" e as "lumières" eram seus atributos, \\ o que implicava em um programa de ação - \\ civilizar o Brasil" (Magnoli, 1997:95)
}

As elites brasileiras do Império se encontravam em uma posição ambígua: se por um lado elas se sentiam parte da mesma civilização européia onde tinham suas origens, do outro lado a imagem do país que governavam não correspondia totalmente aos parâmetros em vigor nas nações européias (como o mapa francês citado anteriormente, o indicava). As tradições científicas do século XIX europeu apontavam para a constituição de academias encarregadas de descrições minuciosas, com levantamentos 
sistemáticos de campo realizados tanto por instituições militares quanto por sociedades de geografia nacionais ${ }^{9}$ capazes de tratar tanto o território nacional como espaços longínquos na Ásia Central, África, América ou Austrália. Segundo as condições políticas do momento, os exemplos a seguir no Império poderiam oscilar entre uma tendência mais inglesa ou francesa ${ }^{10}$, mas os olhares estavam sempre atentos ao que se passava do outro lado do Atlântico.

\section{Documentação civil e engenharia militar. contribuições estrangeiras e identidade nacional}

Os cientistas europeus eram bem-vindos ao Brasil para ajudar a conhecer melhor o país: o engenheiro Harfeld, por exemplo, foi encarregado pelo Império de realizar uma viagem de exploração ao longo do rio São Francisco e de seus afluentes de 1852 a 1854 e como subproduto da sua viagem foi realizado um mapa da província de Minas Gerais na escala de 1: 2.000 .000 em 1855; o francês Emmanuel Liais também percorreu a região um pouco mais tarde entre 1860 e 1870 para coordenar a triangulação de certas partes desta bacia. Na segunda metade do século XIX, outras expedições, desta vez de origem norte-americana, começam a vir : entre 1865 e 1866 a Expedição Thayer estuda a geologia e a geografia física do país; em 1867 a expedição do Smithonian Institution analisa as vias de comunicação do país, sejam elas fluviais ou ferrovias ; enfim, a Expedição Morgan relança o interesse pelos estudos geológicos no norte do país ${ }^{11}$. No entanto, não se pode dizer que todas essas contribuições estrangeiras tenham sido apreciadas positivamente no Brasil. O geógrafo alemão, Robert H. Schomburgk, que havia estado na Guiana Inglesa vizinha entre 1835 e 1838, após seu retorno à Europa e tendo adotado a cidadania inglesa, publica diversos trabalhos, onde reivindica vários territórios da zona fronteira à coroa britânica. Os mapas que acompanham sua descrição da Guiana Inglesa alimentam uma longa discussão sobre os limites entre os dois países, questão que só será resolvida no início do século XX pelo Barão do Rio Branco, com novos mapas. A cartografia serve assim para ganhar territórios, mas também provoca conflitos.

Da mesma maneira, na resolução da questão fundiária interna, os mapas terão um papel fundamental. Em setembro de 1850, a nova lei 601 vincula a propriedade da terra ao seu registro, e nesse sentido, a presença do juiz de terras e sua equipe de escrivães e topógrafos, se tornam figuras chaves na divisão dos bens no país. A imensa quantidade de levantamentos necessários em locais de difícil acesso contribui para dificultar o acesso à propriedade no país. A colonização de novas terras por europeus recém chegados ao país, mobiliza o trabalho de vários engenheiros, muitos deles chegando ao país com os novos colonos. E. Müzell, C. Rivierre e E. Odebrecht são alguns dos nomes que vão progressivamente organizar os mapas de diversas províncias do Império ${ }^{12}$ onde a ocupação progressiva das terras e planaltos aparece ao lado de "terras pouco conhecidas e habitadas por índios". Os espaços em branco nos mapas são vistos como razão de vergonha pela elite letrada do país, que buscava se espelhar em um território "civilizado".

Estas elites nacionais que assumem como um dever patriótico ensinar e divulgar os conhecimentos históricos e geográficos que servem de base à apresentação do país ao mundo, vão se encarregar de criar instituições capazes de legitimar a ordem social que se instala com o Império. Em 1838 é fundando o Instituto Histórico e Geográfico 
Brasileiro, que contrariamente às novas instituições científicas formadas no país, reunia um grupo formado exclusivamente por pessoas da corte do Rio de Janeiro ${ }^{13}$, selecionados mais por suas relações políticas e sociais que por suas produções intelectuais (sobretudo quando se sabe que $75 \%$ do seu orçamento dependiam de fundos públicos):

"E deixar sempre à sabedoria especulativa dos estrangeiros a formulação da nossa história ? (...) Buscamos também ressuscitar os americanos do indigno obscurantismo onde estavam até agora" Revista do IHGB, t. 1, 1839 in Schwarcz (1989).

Mesmo se a geografia ocupa uma posição de menor destaque, com somente $18 \%$ dos textos totais publicados (Schwarcz, 1989), os diferentes mapas que são colecionados (cartas de navegação antigas, cartas hidrográficas e topográficas contemporâneas, mapas de colonização e de novas estradas, e mesmo simples croquis de localização) ajudam não somente a cumprir os objetivos enciclopédicos da instituição, mas podem servir como prova nos diferentes conflitos de limites pendentes.

"Dê-me o mapa de um país, sua configuração, seu clima, suas águas, seus ventos e toda a sua geografia física, informe suas produções naturais, sua flora e sua geologia e eume proponho a dizer À PRIORI qual será o homem deste país" in Revista do IHBG, $n^{2} 2$, 1839, citado em Schwarcz (1989)

O imperador D. Pedro II, protetor do IHGB desde a sua criação, torna-se membro e presidente de honra em 1842 e preside mais de 500 sessões, doando vários manuscritos e publicações ao instituto. Seu interesse é tão importante, que ele é freqüentemente retratado junto a globos e mapas, seja de maneira oficial ou caricatural (ver figura 3). Graças ao seu apoio, o IHGB atinge seu apogeu no Segundo Império, organizando viagens de exploração, como a de 1859 a 1861 no Ceará. Sua lealdade ao regime monárquico persistirá mesmo após a proclamação da república, servindo de exemplo a vários outros institutos históricos e geográficos que aparecem desde a metade do século XIX até o século XX com diferentes orientações ${ }^{14}$. 
Figura 3: D. Pedro II e seus mapas

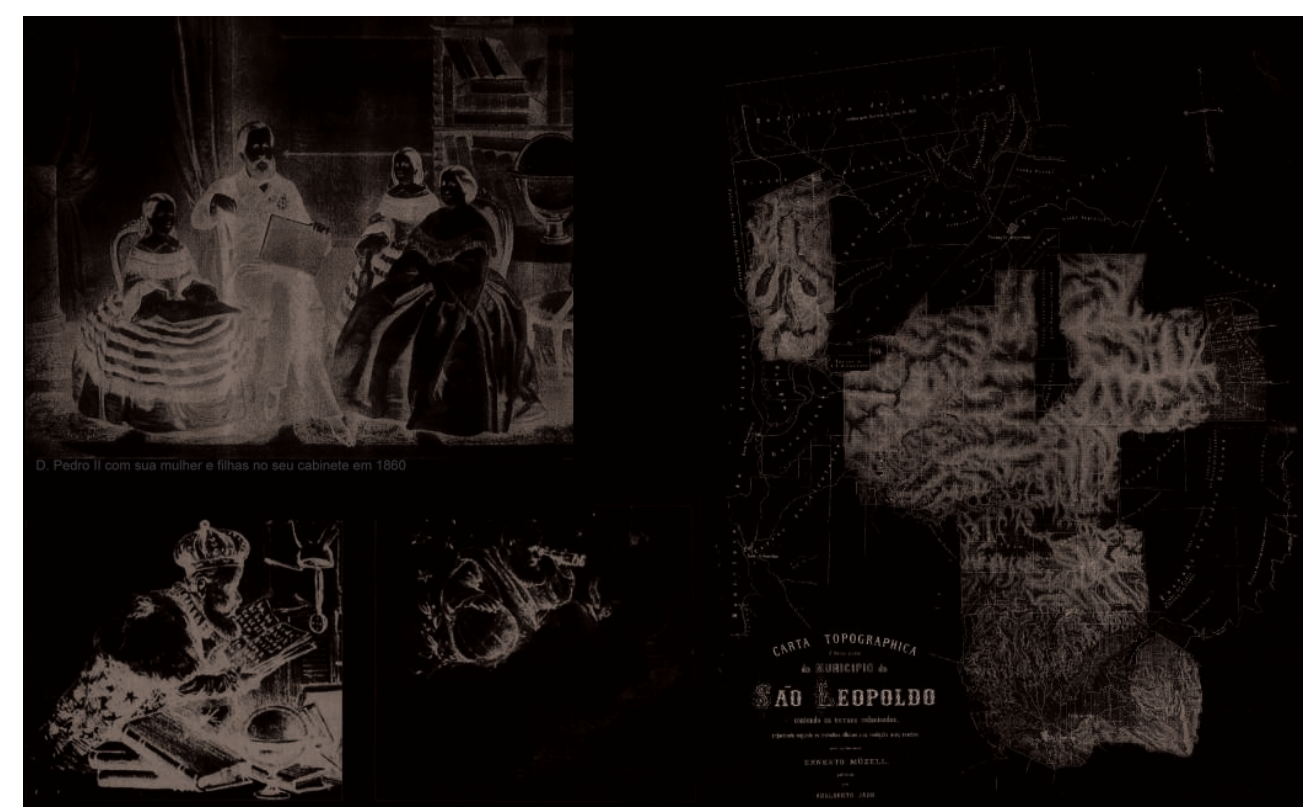

Esq.: D. Pedro II com sua mulher e filhas no seu cabinete em 1860. Embaixo: Caricaturas de D. Pedro II durante seus estudos: sempre com mapas e globos. Dir.: Mapa da coleção particular de D. Pedro II, legado ao IHGB. Ele foi realizado por E. Müzell em 1870 para indicar o estado da colonização no município de São Leopoldo. Rio Grande do Sul. Nota-se a diferença entre as areas de colonização e as outras partes do município.

Fonte: Schwarcz, 1999 e Adonias, 1990

Entre os fundadores do IHGB, aparecem vários brasileiros que assumem um papel importante na elaboração de mapas no período imperial, sendo uma grande parte formada nas escolas militares da época. A primeira instituição técnica criada no país foi a Academia Real da Marinha, no Mosteiro de São Bento, ainda pelo rei João VI na sua chegada ao Rio. Em 1810, outra academia militar, responsável pela formação de oficiais tanto no domínio da artilharia quanto da engenharia topográfica, aparece para assegurar uma formação científica aliada a um conjunto de instruções mais práticas, úteis à ação militar ${ }^{15}$. 0 ensino da Escola Militar do Rio de Janeiro dedicava uma atenção especial à matemática: desde as bases de geometria e de trigonometria esférica, até a astronomia e a geodésia, a matemática aplicada fazia parte dos sete anos de formação propostos. Os civis eram autorizados a seguir os cursos da Academia Militar ${ }^{16}$, às vezes em cursos específicos, até que em 1858 fosse formada a Escola Central, que lhes foi dedicada majoritariamente. Será necessário esperar a reforma do sistema de ensino superior de 1874, para que apareça enfim uma instituição exclusivamente civil como a Escola Politécnica, nos moldes franceses.

"O fato que a engenharia civil fosse dominante não significava que a escola fosse especialmente competente no desenvolvimento das técnicas mecânicas de construção ou no desenvolvimento de competências em ciências físicas ou naturais. (...) O que tornava importante a Escola Politécnica do Rio de Janeiro era, sobretudo, o seu papel na criação de um novo grupo de intelectuais de elite que pudesse por em questão os conhecimentos estabelecidos pelos religiosos e advogados tendo em vista uma ciência moderna. A noção que a sociedade pudesse ser planejada e comandada por engenheiros, o que fazia parte de uma tradição francesa, teria um grande impacto no Brasil." in Schwartzman (1991:68) 
Entre as carreiras civis e militares, o nome do coronel Conrado Jacob Niemeyer aparece como uma das figuras mais dinâmicas da cartografia do início do século XIX. De 1817 a 1824 ele realiza diversos trabalhos em Pernambuco, tais como as plantas de Recife e Olinda, os planos de defesa da costa até a foz do Rio São Francisco e mesmo os estudos para a ligação de linhas telegráficas na região. Passando para a reserva em 1833, ele será responsável por vários outros serviços de inspeção de trabalhos e edifícios públicos, tais como as reformas da Fazenda Imperial Santa $\mathrm{Cruz}^{17}$. Em 1842, com a ajuda do futuro major Pedro d'Alcântara Bellegarde ${ }^{18}$ (que participaria igualmente das demarcações no sul do país), Niemeyer prepara o mapa da Província do Rio de Janeiro, para então realizar os mapas das províncias de Alagoas, Pernambuco, Paraíba, Rio Grande do Norte e Ceará. Finalmente em 1846, o coronel Niemeyer começa a grande carta "chorográphica" do Império do Brasil19, auxiliado por outros membros originários dos círculos militares - o capitão José Joaquim de Lima e Silva e o oficial de engenharia Antônio Augusto Monteiro de Barros. Mesmo indicando que a carta não passaria de um esboço, devendo ser corrigida por trabalhos futuros, Niemeyer consegue avaliar pela primeira vez a superfície do país (estimada em $8337218 \mathrm{~km}^{2}$ ) e de suas províncias, inserindo um quadro estatístico que descreve os principais fatos econômicos do comércio do Império. Com limites que se tornam cada vez mais sistemáticos à medida que se caminha em direção às fronteiras norte, o mapa mostra os principais rios do país, cercados por cadeias de montanhas dispostas geometricamente como nos mapas europeus apresentados na figura 1 . A região da Ilha do Bananal aparece com um grande lago, enquanto as fontes do Araguaia parecem ser bastante dúbias. O "Estado Oriental" (Uruguai) têm uma grande densidade de informações e a cidade do Rio de Janeiro merece um quadro à parte onde estão localizadas as diferentes instituições científicas da cidade. O mapa merece uma medalha de ouro da parte de D. Pedro II, sendo reeditado em 1857 por ordens do Marquês de Caxias (futuro Duque de Caxias) para expor os limites com o Paraguai, no momento em que se pressente o conflito. De fato, a guerra do Paraguai, que se inicia em 1864, será a ocasião de afirmar definitivamente o papel das forças armadas brasileiras, impulsionando ainda mais a realização de estudos e mapas hidrográficos do interior do país ${ }^{20}$,

\section{Apogeu e declínio do Império: os mapas e atlas gerais do Império e o desafio da cartografia interna}

30 A guerra do Paraguai, iniciada com euforia, provoca um grande desgaste tanto financeiro quanto político no regime imperial. Depois de oito anos de conflito, um novo mapa geral do Império será preparado em 1873, como uma nova oportunidade para apresentar o país na exposição universal de Viena ${ }^{21}$. Na ocasião, o Barão de Ponte Ribeiro retoma os trabalhos de Conrado Jacob Niemeyer e atualiza as fronteiras com os estados limítrofes, especialmente os limites com a República do Paraguai, única parte do mapa no exterior do país caracterizada por uma grande densidade de topônimos (ver figura 4). Outros limites do Mato Grosso com a República da Bolívia e mesmo com as províncias do norte do país, mostram demarcações ainda incertas. Com o meridiano do Rio de Janeiro ao centro, o mapa retoma o esquema de representações esquemáticas de montanhas nas divisas de várias províncias, diferenciadas com cores distintas. 
Figura 4: 0 mapa geral do Império de 1873

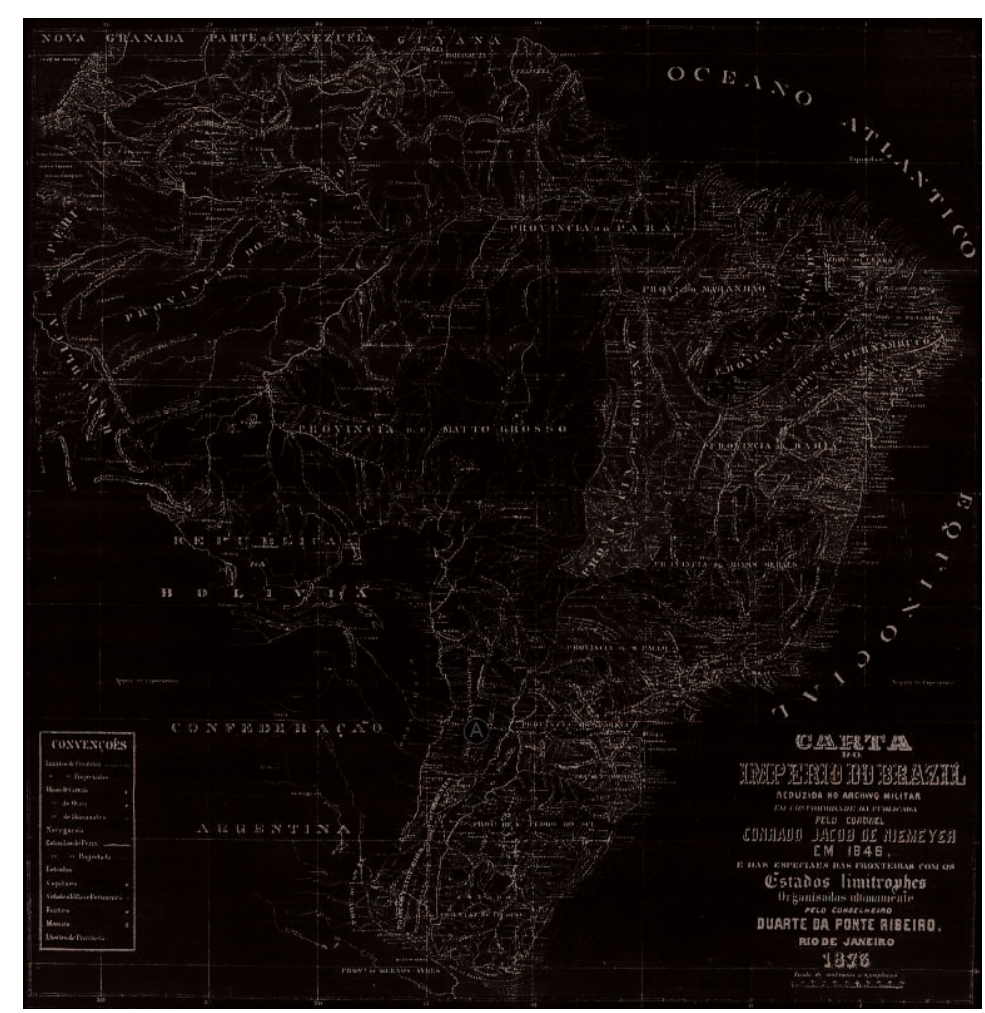

Fonte: Mota e Lopes, 1989

31 Os grandes mapas de síntese se sucedem. No ano de 1875 será publicada um novo Mapa do Império do Brasil, na escala de 1:3.710.220, ainda com o auxílio de Ponte Ribeiro, mas organizado pela Comissão do Mapa Geral do Império. Esta comissão era presidida pelo General Henrique de Beaurepaire Rohan, símbolo da nova cartografia essencialmente brasileira. Filho de geógrafo, Beaurepaire Rohan se tornou membro do IHGB após ter publicado suas viagens ao interior do país, indo de Cuiabá ao Rio de Janeiro, primeiro por vias fluviais até a foz do Rio de la Plata, seguindo por um trajeto marítimo de Rio Grande até a capital, recolhendo informações que seriam muito úteis, quando, como militar, participou da Guerra do Paraguai. O mapa de 1875 que organiza, se apóia tanto na coleção de mapas existentes nas coleções nacionais quanto nos levantamentos mais recentes, sem contudo seguir uma cobertura de levantamentos geodésicos sistemáticos, como os que eram feitos na Europa de então. O trabalho final de adequação e síntese deverá equilibrar uma informação necessariamente heterogênea, segundo as regiões do país, testemunho de diferentes graus de ocupação e controle do território. Em estudo posterior $^{22}$, Beaurepaire Rohan identifica as fontes disponíveis no momento da realização do mapa:

- 85 mapas para a parte setentrional (dos quais 32 provinham das comissões de limites do Tratado de São Ildefonso)

- 43 mapas para a parte ocidental

- 45 mapas para a parte meridional

- 116 mapas para a parte oriental

- 17 mapas para a parte central

- 15 mapas pelo menos de uma das partes acima descritas

- 9 mapas representando o país inteiro 
Desta maneira se compreende porque o mapa indica o nome das províncias, sem insistir sobre os seus limites - no interior do país somente os principais elementos de hidrografia e as montanhas situadas em locais estratégicos tais como a passagem entre as duas grandes bacias amazônica e platina são situadas. Além das fronteiras do Império, os limites entre os outros Estados sul-americanos só são sugeridos no mapa graças aos nomes de países: Estado Oriental (Uruguai), Confederação Argentina, República do Paraguai, República do Chile, República da Bolívia, Nova Granada, Venezuela $\mathrm{e}$ as Guianas. $\mathrm{O}$ mesmo contraste entre as fronteiras internacionais meridionais, traçadas de maneira detalhada, aparece face aos contornos mais esquemáticos nas fronteiras setentrionais. Na legenda aparecem os sinais da civilização brasileira: a capital, as vilas e vilarejos, as estradas de ferro construídas e projetadas, os fortes militares formando um território onde se consolida a ocupação do imenso espaço delimitado.

No mesmo ano de 1875, é criada a Comissão Geológica Imperial, tentativa de coordenar a ocupação e a consolidação territorial do país. Composta de civis e militares, capacitados em diferentes disciplinas, a comissão foi encarregada de realizar um inventário dos recursos naturais do país, desta vez nos moldes da US Geological Survey, que desde 1879 realiza levantamentos topográficos e geológicos, voltados à exploração das riquezas minerais norte-americanas. Símbolo de uma nova influência, que começa a se impor no cenário da cartografia brasileira, a comissão é coordenada pelo canadense Charles F. Hartt, acompanhado por outros geólogos norte-americanos que se estabelecerão de maneira mais prolongada no país, como Orville Derby ${ }^{23}$. Apesar de durar apenas dois anos, a Comissão consegue reunir mais de 500.000 amostras de rochas, plantas e animais, ajudando a enriquecer a massa de documentos existentes para a realização do Mapa Geral do Império. Ela servirá de exemplo para a constituição de outras instituições, movidas pela mesma visão positivista de uma ciência, guiando a apropriação do território em várias províncias, principalmente naquelas em que o desenvolvimento econômico favorecia a realização de estudos mais detalhados ${ }^{24}$.

34 A cartografia de síntese do Império transparece igualmente em uma série de atlas, dedicados ao poucos alunos do ensino publico do ensino médio e superior existentes. Destinado aos alunos do Liceu Imperial D. Pedro II, o "Atlas do Império do Brasil" organizado por Cândido Mendes de Almeida em 1868 se inspira em representações inglesas e francesas, mas apresenta cada província e suas comarcas, com divisões administrativas, eclesiásticas, eleitorais e judiciárias - fato surpreendente quando se considera os inúmeros conflitos entre as províncias na época ${ }^{25}$. Outros atlas escolares podem ser citados: o atlas de Lomelino de Carvalho, de 1882, e o"Atlas do Império do Brasil" do Barão Homem de Melo e do Coronel Pimenta Bueno, de 1889, reeditado diversas vezes, mesmo no período republicano ${ }^{26}$. Nesta série de representações unificadas e únicas, o Império confirma assim o seu efeito centralizador, capaz de criar emblemas que serão duráveis na cultura brasileira.

35 A transição republicana, anunciada pela crise política que se inicia com a Guerra do Paraguai, reforçará o poder dos militares e de novas elites regionais. No entanto, no que diz respeito às tradições de representações cartográficas em uso no país, as bases lançadas no Império parecem ultrapassar a troca de regime.

36 O argumento cartográfico com seus critérios de "forma, unificação e valorização do território" continuará a ser usado pela diplomacia brasileira no final do século XIX e início do século XX, para finalizar a delimitação das fronteiras septentrionais e nas 
relações com países vizinhos pelos sucessores do Barão de Ponte Ribeiro, como o Visconde e o Barão de Rio Branco. Este último será capaz de articular o discurso cartográfico, de maneira a se impor nos meios acadêmicos e diplomáticos internacionais, ${ }^{27}$ com realizações originais, frutos de um trabalho importante de recuperação de fontes diversas. Sua ação diplomática, fiel às tradições cartográficas do Império, chega a ser chamada de pacifista, pois o intenso uso do discurso cartográfico parece legitimar a defesa dos interesses nacionalistas, sem ocasionar conflitos armados. Aliando um extenso trabalho de documentação e criação cartográfica, Rio Branco será responsável pela delimitação de $5.062 \mathrm{~km}$, após os $7.948 \mathrm{~km}$ de fronteiras continentais estabelecidas nos tempos do Império. Estas linhas firmes que asseguram a presença do país de maneira definitiva nos mapas no início do século XX abrem espaço para o desafio de conhecer um território imenso de 8,5 milhões de $\mathrm{km}^{2}$.

\section{BIBLIOGRAFIA}

ADONIAS I. (1960) Mapas e planos manuscritos relativos ao Brasil colonial (conservado no Ministério das Relações Exteriores e descritos por Isa Adonias para a comemoração do V centenário da morte do Infante D. Henrique) - 1500-1822. Rio de Janeiro, Ministério das Relações Exteriores/Serviço de Documentação.

ADONIAS I. (1990) O IHGB 150 anos. Rio de Janeiro, Studio HMF.

ADONIAS I. (1993) MAPA Imagens da formação territorial brasileira. Rio de Janeiro, Fundação Emilio Odebrecht.

CARVALHO D. de (1939) “As fronteiras do Brasil no regime colonial” in Revista de Geografia, Rio de Janeiro, ano I, n 4, out. 1939, p. 91-109.

CASTRO N.W. (1994) Missão na selva : Emil Oderbrecht - 1835-1912: um prussiano no Brasil. Rio de Janeiro, AC \&M.

CORTESAO J. (1965/1966) História do Brasil nos velhos mapas. Rio de Janeiro, Instituto Rio Branco, tomos I e II.

DE BIAGGI E.M . (2000) « La cartographie et les représentations du territoire au Brésil » Tese de doutorado defendida em 07/12/2000 na Université de la Sorbonne Nouvelle - Paris III/ Institut des Hautes Études de l'Amérique Latine Paris, dirigida por Jean Revel-Mouroz.

DE BIAGGI E.M. \& DROULERS M. (2000) « Cartographie et formation territoriale » in « Redecouvrir le Brésil » Cahiers des Amériques Latines, IHEAL, n³4, p. 39-60.

DE BIAGGI E.M. \& DROULERS M. (2003) «L'île Brésil : la force d'un mythe cartographique » in Mappemonde 69, vol.1, p. 40-43.

DROULERS M . (2001) Brésil, une géohistoire. Paris, PUF.

FURTADO S.S. (1959) Estudo das cartas históricas da mapoteca da Diretoria do Serviço geográfico - a cartografia luso-brasileira. Rio de Janeiro, Estado maior do Exército. 
GUILLAUMON J.R. (org) (1996) Pesquisando São Paulo - 110 anos de criação da Comissão Geográfica Geológica. São Paulo, IGC.

GOES FILHO S.S. (1999) Navegantes, bandeirantes, diplomatas - um estudo sobre as formações de fronteiras do Brasil. São Paulo, Martins Fontes.

COULD P. \& BAILLY A. (1995) Le pouvoir des cartes - Brian Harley et la cartographie. Paris, Anthropos/Economica.

HARLEY B. (1991) “A nova história da cartografia” in Correio da UNESCO, agosto 1991, ano 19, n8 Brasil, p. 4-9.

MAGNOLI D. (1997) O corpo da pátria : imaginação geográfica e política externa no Brasil (1808-1912). São Paulo, Ed. UNESP/Moderna.

MOTA C.G.\& LOPEZ (1989) Brasil revisitado - palavras e imagens. São Paulo, Editora Rios.

PORTIER R. (1991) «Imagerie, imaginaire et stratégie territoriales » in THERY, H. (dir) L'État et les stratégies du territoire. Paris, Éditions du CNRS.

PEREIRA J.V. da C. (1956) “A geografia no Brasil” in AZEVEDO F. (org.) As ciências no Brasil. Ed. Melhoramentos, p. 315-412.

RESENDE M.E.L. \& MORAES A.M. (1987) Atlas Histórico do Brasil. Belo Horizonte, Vigilia.

SCHWARCZ L.K.M. (1989) Os guardiões da nossa história oficial. São Paulo, Série História das ciências Sociais, IDESP.

SCHWARCZ L.K.M. (1999) As barbas do imperador - D. Pedro II, um monarco nos trópicas. São Paulo, Companhia das Letras.

SCHWARTZMAN S. (1991) A space for science : the development of scientific community in Brazil. Pennsylvania, The Pennsylvania State University.

\section{NOTAS}

1. De fato, Portugal deveria receber 2 milhões de libras inglesas como indenização pela perda da colônia, exatamente o valor da dívida portuguesa com a Inglaterra : o ouro brasileiro foi assim transferido diretamente aos ingleses, únicos favorecidos pelo acordo.

2. No momento da independência em 1822 , somente 8 províncias reconhecem o novo governo: nas províncias do norte, Rio Negro e Pará, bem como no Maranhão e Bahia, o apego à Portugal deu origem à conflitos entre forças portuguesas e brasileiras até a capitulação final das tropas portuguesas em julho de 1823. Da mesma maneira, em 1824, a Confederação do Equador em Pernambuco, Ceará, Rio Grande do Norte e Paraíba se diferencia com uma proposta republicana de governo, fato que se repete ainda no período da regência (1831-1840) com novos movimentos separatistas : a "Cabanagem" (1835-1840) com mais de 30000 mortes na Província do Pará; a "Sabinada" na Bahia (1837-1938), a "Balaiada" no Maranhão (1838-1841), as revoltas "Farroupilhas" com a República de Piratini (1835-1845) no Rio Grande, e a República Juliana em Santa Catarina (1839).

3. $O$ único local onde se pode ter uma idéia das fontes que permitiram a confecção do mapa e do texto que o acompanha é onde se apresenta as estimativas de população, baseadas, segundo o autor, nos escritos de Schaeffer, sem mais precisões. Poderia ser Aloys von Schaeffer, que em 1824 publicou um livro "O Brasil como Império independente" (ver Magnoli, 1997, pag. 107).

4. Goes Filho (1999) faz a distinção entre o 'uti possidetis juris (de direito) e o uti possidetis de facto, segundo a literatura em língua espanhola. O primeiro, a posse da terra segundo os tratados 
coloniais que os delimitam, seria uma resposta à idéia brasileira de reconhecer a posse da terra aos que a ocupam efetivamente.

5. Adonias (1960) conta de fato a história de um conjunto de 15 mapas portugueses do final do século XVIII, que Ponte Ribeiro encontrou na sua estada em Buenos Aires em 1843. Sabendo que estes mapas haviam sido roubados do Governo do Pará alguns anos antes, o diplomata não hesitou em retomá-las e levá-las de volta ao Brasil utilizando os mesmos métodos que os levaram à posse argentina, principalmente porque esses mapas se tornaram importantes para a definição das fronteiras de Pirara e Tabatinga - ao norte e ao oeste da Amazônia.

6. Ao todo, o Barão Ponte Ribeiro redigiu mais de 180 tratados sobre este assunto - ver Adonias, 1960 e Goes Filho, 1999.

7. Realizadas pelo Barão de Caçapava, o Marechal Francisco José de Souza Soares d'Andréa, os trabalhos de triangulação foram depois estendidos por Bellegarde a toda a região da Lagoa Mirim. Pensou-se mesmo em realizar a triangulação de toda a província, considerada estratégica para o equilíbrio das forças na bacia Platina, o que não foi feito. Mas a presença militar na região, especialmente no que diz respeito aos trabalhos de cartografia de base, foi sempre muito importante. Em 1903, no momento da criação da Comissão da Carta Geral do Brasil, feita pelo Estado Maior das Forças Armadas, o começo dos trabalhos foi feito em Porto Alegre, com a recuperação das redes geodésicas locais.

8. A doação desta coleção ao Estado, após a sua morte, constituiu o primeiro embrião da mapoteca do Ministério das Relações Exteriores brasileiro, o Itamaraty.

9. A Société de Géographie de Paris (1821), a Royal Geographical Society de Londres (1830), foram seguidas bem mais tarde, pelos seus equivalentes como a National Geographical Society fundada em 1898 em Washington.

10. Pereira (1956) faz a relação entre uma maior influência inglesa ou francesa segundo o poder dos seus representantes mais importantes no Império, o Conde de Linhares (inglesa) ou o Conde da Barca (francesa).

11. Mais detalhes sobre as expedições e viagens de no Brasil ao longo do século XIX, entre outros, em Pereira (1956).

12. E. Müzell faz uma carta topográfica do município de São Leopoldo no Rio Grande do Sul, onde a afetação de terras às colônias alemãs é descrita em 1870. C. Rivierre contribui para a organização do mapa da província do Espírito Santo (1878) e no mapa da nova província do Paraná. Os diferentes trabalhos de E. Odebrecht foram recenseados no livro de Castro (1994) que descreve a importância dos topógrafos na demarcação dos lotes dos colonos, bem como nas diferentes missões preparatórias à abertura da estrada permitindo o acesso ao alto vale do Itajaí. E. Oderbrecht, após uma primeira estadia no sul do país, retorna à Europa justamente para se formar engenheiro topógrafo e poder assim contribuir à colonização catarinense.

13. O museu imperial, antigo museu real no tempo da presença da corte portuguesa no Brasil, tinha sido formado com a coleção do mineralogista alemão Abraham Werner. Durante todo o século XIX, as coleções foram enriquecidas pela vinda de diversos naturalistas estrangeiros como Langsdorff, Friedrich Sellow, Fritz Muller, e outros (Schwartzman, 1991).

14. Mais de 20 institutos históricos e geográficos aparecerão desde o Amazonas até Santa Catarina, buscando sempre recuperar as identidades locais, mas servindo às vezes como tribunas de críticas ao centralismo do Império.

15. Em 1832, as duas academias são reagrupadas, mas a união só durou um ano, após o qual cada escola procurou desenvolver um ensino mais específico aos objetivos finais do seu corpo militar.

16. Nesta época, segundo Schwartzman (1991), a profissão militar não tinha muito prestígio no Brasil, à exceção da região próxima da fronteira sul, e as dimensões civis da Escola sempre foram privilegiadas. D. Pedro II também desdenhava os militares, tendo proferido discursos onde mostrava claramente sua preferência por estudiosos que se dedicavam ao estudo de matemáticas, de astronomia e de engenharia(ver Schwarcz,1999:299). 
17. A Fazenda Santa Cruz, antiga propriedade dos jesuitas que, após sua expulsão do país, passou a pertencer à corôa portuguesa, era conhecida por ensinar música e canto aos escravos que lá viviam.

D. João VI, encantado pela orquestra e pelo côro local, salva a fazenda da decadência que ela havia conhecido após a partida dos jesuitas e recupera principalmente o ensino musical. Tornando-se a Fazenda Imperial Santa Cruz, ela era uma residência de verão para D. Pedro II antes da construção de Petrópolis.

18. Tanto Niemeyer quanto Bellegarde, membros do corpo imperial de engenheiros do Império, participam da fundação do IHGB. O Major Bellegarde ensinava também na Academia Militar e seus livros disáticos e de divulgação marcam a história da cartografia imperial. Furtado (1959) indica os elos familiares entre os dois engenheiros cartógrafos - Bellegarde era sobrinho de Niemeyer.

19. Quando consultamos a edição de 1857 da carta de Niemeyer na Bibliothèque Nationale de Paris, o fato de ela ser de grande tamanho, com elementos coloridos, impediu a sua reprodução neste texto. Sua comparação com outros documentos ali presentes, como o mapa do Império do Brasil de Beaurepaire Rohan, do "mappa dos Estados Unidos do Brasil feito pelo Barão de Rio Branco e o Mapa que comemora o centenário da independência brasileira, organizado pelo Clube de engenheiros em 1922, mostra vários elementos em comum. Para o mapa de Niemeyer, encontramos uma reprodução de um outro mapa feito pelo Barão de Ponte Ribeiro, baseado em seus trabalhos, apresentado na figura 4.

20. Em 1876 foi criada a Repartição Hidrográfica da Marinha, encarregada de coordenar a direção de estudos hidrográficos no país. Mais tarde chamada Direção hHidrográfica de Navegação (DHN), este serviço será o responsável da criação do primeiro plano nacional de cartografia náutica em 1935. O atlas histórico da Guerra do Paraguay, organizado pelo oficial E.C. Jourdan, em 1871 mostra a importância dos mapas nesta situação de conflitos em regiões de difícil acesso.

21. Além de realizar exposições nacionais, o imperador prestava uma atenção especial à participação do Brasil nas exposições universais da segunda metade do século XIX, considerada como uma opurtunidade única de mudar a imagem do país internacionalmente, dando-lhe uma aura civilizada. Desde a sua primeira particpação em 1862, em Londres, o pais apresentava tantos produtos naturais, quanto objetos testemunhando a indústria nacional (Schwarcz, 1999). Os mapas faziam parte deste segundo tipo do objeto, considerados como símbolos de desenvolvimento.

22. Em 1877, Beaurepaire Rohan publica um estudo sobre a organização do mapa geográfico e da história física e política do Brasil, o equivalente a um enfoque choreográfico do país, expondo as fontes e mapas utilizados.

23. O geólogo O. Derby fazia parte da seção de mineralogia e geologia do Museu Nacional. Ele presidirá a Comissão Geológica e Geográfica (CGG) de São Paulo até 1905, quando começa a participar do Serviço Geológico e Mineralógico do Brasil. Neste sentido, ele auxilia a publicação de mapas dos estados de Ceará, Rio Grande do Norte, Paraíba, Pernambuco, Piauí e Bahia em 1910. A base desses mapas será o Mapa da República publicado em 1895. Seu primeiro assistente em 1886 foi o engenheiro Theodoro F. Sampaio, substituído em 1892 por Horace Williams, que atualiza os métodos geodésicos da comissão (Guillaumon, 1996).

24. A Comissão Geológica e Geográfica (CGG) de São Paulo foi fundada em 1886 como uma reação à "ausência de informações exatas e minuciosas sobre a geografia, relevo, solo,vias de comunicação, estrutura geológica, riqueza mineral e o caráter de diversas qualidades de terras", nas palavras do presidente da província, o Conselheiro João A. Correia de Oliveira (Guillaumon, 1996). A CGG comça uma operação de triangulação do território em 1886,a partir da medida da base de Campo Largo, fazendo explorações de exploração no sul e no oeste da Província, nos rios Paranapanema e Itapetininga, em 1886, e Tietê, Feio, Aguapeí, Paraná e Peixe em 1905. Segundo Lefèvre (1944 in Santos 1983) em 1897, já havia 30 folhas de mapas topográficos realizados na 
escala 1:100 000, devendo ser impressos em 3 cores, tendo como referência o meridiano do Rio de Janeiro.

25. As disputas entre províncias vão constituir uma boa parte dos trabalhos de organização territorial no momento da criação do IBGE na década de 1930. Certas áreas problemáticas persistirão durante mais de um século, como a questão dos limites entre Ceará e Piauí.

26. Tendo participado de diferentes viagens de exploração, o Barão Homem de Melo deve seu título a sua carreira de professor e parlamentar, bem como à sua grande produção de mapas topográficos. No momento da publicação de seu atlas, ele ensinava na Escola Militar do Rio de Janeiro, sendo um dos responsáveis pela divulgação do sistema métrico nos trabalhos cartográficos e geodésicos (anteriormente as léguas eram mais utilizadas). Em 1909, ele remodela seu atlas, atualizando os 33 mapas que ele continha.

27. O Barão de Rio Branco, membro e presidente do IHGB, contribui na redação do artigo sobre o Brasil na Grande Encyclopédie de Émile Levasseur, que o apresentará à Société de Géographie de Paris para que seja membro. Rio Branco será também correspondente-associado da Royal Society de Londres. Fiel ao centralismo da época do império, o Barão nunca abandonou o uso do nome "Rio Branco", adquirido por decreto da Princesa Isabel em 1888, como uma homenagem à memória de seu pai. O detalhe de suas negociações é descrito entre outros em Magnoli (1997), De Biaggi (2000) e Droulers (2001).

\section{RESUMOS}

No momento da independência, os documentos cartográficos reunidos no Brasil são mobilizados para reforçar o argumento tradicional "uti possedetis" de posse, para lidar com os vários litígios de fronteiras típicos das novas nações sul americanas. A indefinição de limites do país permanece ao longo de todo o século XIX, mas a diplomacia brasileira consegue progressivamente justificar a ocupação real das terras, fazendo um uso hábil dos mapas disponíveis. Os mapas do Império buscam dar uma imagem positiva do país, mostrando o caráter "civilizado" da nova nação. Realizados por civis e militares formados nas novas escolas brasileiras, estrangeiros e brasileiros se sucedem nas novas instituições responsáveis pela cartografia nacional. Sem meios de realizar um levantamento sistemático total do país, os novos mapas são frutos de extensas compilações e não fornecem detalhes sobre a distribuição e a gestão interna do imenso território brasileiro.

Au moment de l'Indépendance, la documentation cartographique rassemblée au Brésil vient renforcer l'argument "uti possedetis" et permet de sortir des litiges frontaliers. L'indétermination des frontières restera visible dans les cartes tout au long du XIXe siècle, et c'est une des forces diplomatiques du Brésil que d'avoir su attendre d'être en mesure de combiner la réalité de l'occupation avec un usage très habile des cartes. La cartographie dans l'Empire sert à donner une image positive du pays ; montrant le caractère "civilisé" de l'État. Réalisée par militaires et les ingénieurs formés dans les nouveaux organismes de formation créés à l'époque, étrangers et brésiliens se succèdent dans les nouvelles institutions responsables de la cartographie nationale. Sans pouvoir compter sur un travail de levés à une échelle plus grande sur un terrain si vaste qu'il dépasse la capacité de ses dirigeants à le saisir en détail, les nouvelles cartes s'appuient sur la compilation de documents disponibles à l'époque et touchent peu à la distribution et à la gestion des terres existantes à l'intérieur du pays. 
At the time of independence, all available maps in Brazil were used to support the traditional argument of the "uti possedetis" in order to deal with the many frontier conflicts emerging from the creation of new countries in South America. The Brazilian frontiers remained undetermined throughout the XIXth century, but Brazilian diplomacy managed to progressively justify the actual occupation of land thanks to an intelligent use of the available maps. The maps of the Brazilian Empire were used to give a positive image of the new country, showing it as part of a great "civilized" world. Designed by both military and civilians which were formed in the new schools, foreigners and Brazilians succeeded to form new leaders of the national cartography. With few means to lead vast surveying campaigns throughout the huge space constituting their country, most new maps are based on a study of previous maps and rarely tended to give extensive details of the newly occupied lands and also the problems deriving from their management.

\section{ÍNDICE}

Palavras-chave: mapas, cartografia, Brasil, independência, formação territorial, fronteiras Índice geográfico: Brasil

Keywords: map, cartography, Brazil, independence, territorial formation, frontiers

Mots-clés: carte, cartographie, Brésil, indépendance, formation territoriale, frontières

\section{AUTOR}

ENALI DE BIAGGI

Université Jean Moulin Lyon 3 - UMR 5600 EVS 